\title{
Pathology of the Lungs in Mitral Stenosis in Relation to Respiratory Function and Pulmonary Hæmodynamics
}

\author{
S. C. JORDAN, ^ P. HICKEN, D. A. WATSON, D. HEATH, and W. WHITAKER \\ From the Departments of Cardiology and Thoracic Surgery, the General Infirmary at Leeds, and the \\ Department of Pathology, University of Birmingham
}

In mitral stenosis, chronic rises in left atrial pressure lead to progressive changes in the structure and function of the lungs: these have been reviewed by Arnott in his Croonian lectures of 1963 . We have investigated a small group of patients with this disease in order to study the relation between histological changes in their lungs and abnormalities in their pulmonary hæmodynamics and respiratory function.

\section{Patients Studied and Observations}

The group consisted of 20 patients (Table I). All but three (Cases 4, 8, and 16) were women. All had rheumatic mitral stenosis; in addition one (Case 8) had slight mitral regurgitation, one (Case 19) had slight aortic regurgitation, one (Case 16) had mild emphysema, and one (Case 13) had previously had a pulmonary embolism. One patient (Case 14) had previously had a mitral valvotomy, but restenosis necessitated a second operation.

(1) Clinical. (a) The grade of dyspnœa was assessed arbitrarily on the following criteria.

Grade 1. Dyspnoea on strenuous effort, such as running for a bus.

Grade 2. Mild dyspnoea on normal activity, such as climbing stairs.

Grade 3. More severe dyspnœe, requiring stops after one flight of stairs or sooner.

Grade 4. Severe dyspnoea, limiting activity to walking slowly less than 100 yards on the level.

The duration of dyspncea was noted.

(b) The occurrence of hæmoptysis was recorded.

(2) Radiological. Routine teleradiographs of the chest were taken and were studied for evidence of hæmo-

Received March 18, 1965.

^ Present address: National Heart Hospital, London W.1. siderosis and basal horizontal lines. Radiographic evidence of pulmonary arterial hypertension in the form of dilatation of the pulmonary trunk and its main branches was also noted.

(3) Pulmonary hamodynamics. Right heart catheterization was carried out in all but one patient to record the pulmonary artery pressure and to collect mixed venous blood samples for estimation of cardiac output by the Fick method. In 9 patients pulmonary arterial "wedge" pressures were recorded, and in 10 patients the left atrial pressure was measured directly by transseptal catheterization. The pulmonary vascular resistance (in units $\mathrm{m}^{2}$ ) was calculated from the mean transpulmonary pressure (in $\mathrm{mm}$. $\mathrm{Hg}$ ) divided by the cardiac index in $1 . / \mathrm{min} . \mathrm{m} .{ }^{2}$ Moderately heavy sedation was used with morphia and sometimes with additional barbiturates.

(4) Mitral valve size. In all but two patients the area of the mitral valve orifice was calculated from approximate estimates of the long and short diameters of the valve obtained at operation. The area of the orifice was expressed relative to body surface area as sq. cm. m.2

(5) Respiratory function. (a) Lung volumes were measured using a Godart Pulmotest spirometer. A Cambridge helium indicator was used in addition for the measurement of the residual volume.

(b) The maximum breathing capacity (direct) and the one-second forced expiratory volume $\left(\mathrm{FEV}_{1}\right)$ were also measured by this apparatus. Normal values for the maximum breathing capacity and vital capacity were obtained from the data of Baldwin, Cournand, and Richards (1948).

(c) The diffusing capacity was measured by the single breath method of Ogilvie et al. (1957). The predicted 
normal values were calculated from their regression equation:

$$
\mathrm{DL}_{\mathrm{CO}}=18.85 \times \text { body surface area }-6.8 \text {. }
$$

(6) Pathological studies. At valvotomy the tip of the lingula was resected and fixed in formal saline; this site was used for operative convenience. Thin paraffin sections were stained with hæmatoxylin and eosin, by the Lawson modification of the Weigert-Sheridan method to demonstrate elastic tissue, muscle, and collagen, and by the Prussian Blue reaction to demonstrate ferric iron in macrophages (hæmosiderosis). The following observations were made:

(a) The alveolar walls were examined for evidence of fibrous thickening.

(b) An examination was made for foci of hæmosiderin-laden macrophages (pulmonary hæmosiderosis).

(c) The presence of dilated lymphatic vessels around pulmonary arteries ("pulmonary lymphangiectasis") in the pleura and in fibrous tissue septa was noted.

(d) The small "muscular pulmonary arteries", between 80 and $500 \mu$ in external diameter, were examined for evidence of medial hypertrophy and intimal proliferation. The thickness of the media of circular muscle was expressed as a percentage of the external diameter of the vessel. The upper limit of normal medial thickness was taken to be 6.8 per cent (Heath and Best, 1958). Intimal fibrosis was expressed as a percentage of the internal diameter of the vessel. Many arteries were measured and mean values for the thickness of the media and intimal fibrosis were calculated. The grade of hypertensive pulmonary vascular disease was determined on the criteria of Heath and Edwards (1958).

(e) The presence of abnormal muscularized pulmonary arterioles was detected. The criterion for their recognition was a distinct media of circular muscle sandwiched between internal and external elastic laminæ in an arterial vessel below $80 \mu$ in diameter.

\section{RESULTS}

The data are recorded as follows: clinical data in Table I; radiological findings in Table II; pulmonary hæmodynamics and mitral valve size in Table III; results of respiratory function tests in Table IV; and histological data in Table V.

\section{Discussion}

We have confirmed our previous findings (Heath and Whitaker, 1955) that pulmonary arterial hypertension in mitral stenosis is associated with increased medial thickness in the small "muscular pulmonary arteries" between 80 and $500 \mu$ in external diameter, and the development of a distinct media of circular muscle in "pulmonary arterioles" (less than $80 \mu$ in diameter). In our previous study we accepted "medial hypertrophy" as medial thickness exceeding 15 per cent of the external diameter
TABLE I

CLINICAL DATA

\begin{tabular}{|c|c|c|c|c|}
\hline \multirow{2}{*}{ Case No. } & \multirow{2}{*}{ Age (yr.) } & \multicolumn{2}{|c|}{ Dyspncea } & \multirow{2}{*}{ Hæmoptysis } \\
\hline & & Grade & $\underset{(y r .)}{\text { Duration }}$ & \\
\hline $\begin{array}{r}1 \\
2 \\
3 \\
4 \\
5 \\
6 \\
7 \\
8 \\
9 \\
10 \\
11 \\
12 \\
13 \\
14 \\
15 \\
16 \\
17 \\
18 \\
19 \\
20\end{array}$ & $\begin{array}{l}37 \\
36 \\
30 \\
39 \\
34 \\
36 \\
32 \\
35 \\
51 \\
35 \\
27 \\
32 \\
31 \\
39 \\
31 \\
55 \\
31 \\
38 \\
38 \\
45\end{array}$ & $\begin{array}{l}2 \\
3 \\
2 \\
4 \\
2 \\
3 \\
2 \\
2 \\
4 \\
2 \\
2 \\
1 \\
3 \\
4 \\
2 \\
3 \\
3 \\
2 \\
2 \\
3\end{array}$ & $\begin{array}{r}5 \\
5 \\
5 \\
20 \\
3 \\
6 \\
2 \\
2 \\
2 \\
3 \\
2 \\
1 \\
2 \\
10 \\
2 \\
7 \\
5 \\
2 \\
4 \\
10\end{array}$ & $\begin{array}{l}0 \\
+ \\
+ \\
0 \\
0 \\
0 \\
0 \\
0 \\
0 \\
0 \\
0 \\
0 \\
+ \\
0 \\
0 \\
0 \\
+ \\
0 \\
0 \\
0\end{array}$ \\
\hline
\end{tabular}

$+=$ present $; 0=$ absent

TABLE II

RADIOLOGICAL FINDINGS

\begin{tabular}{|c|c|c|c|}
\hline Case No. & Hæmosiderosis & $\begin{array}{c}\text { Horizontal } \\
\text { lines }\end{array}$ & $\begin{array}{l}\text { Dilatation of } \\
\text { pulmonary trunk } \\
\text { and its main } \\
\text { branches }\end{array}$ \\
\hline $\begin{array}{r}1 \\
2 \\
3 \\
4 \\
5 \\
6 \\
7 \\
8 \\
9 \\
10 \\
11 \\
12 \\
13 \\
14 \\
15 \\
16 \\
17 \\
18 \\
19 \\
20\end{array}$ & $\begin{array}{l}+ \\
+ \\
0 \\
0 \\
0 \\
+ \\
0 \\
+ \\
0 \\
0 \\
0 \\
0 \\
0 \\
+ \\
0 \\
0 \\
0 \\
0 \\
0 \\
0\end{array}$ & $\begin{array}{l}+ \\
+ \\
+ \\
0 \\
+ \\
+ \\
+ \\
0 \\
+ \\
+ \\
0 \\
0 \\
+ \\
+ \\
+ \\
0 \\
+ \\
0 \\
0 \\
+\end{array}$ & $\begin{array}{l}2 \\
2 \\
1 \\
2 \\
0 \\
2 \\
2 \\
1 \\
1 \\
1 \\
1 \\
0 \\
1 \\
1 \\
1 \\
0 \\
2 \\
0 \\
1 \\
0\end{array}$ \\
\hline
\end{tabular}

$+=$ present $; 0=$ absent $; 1=$ equivocal; $2=$ abnormal .

of pulmonary arteries, and we found this degree of muscularization in the majority of patients whose pulmonary arterial mean pressure exceeded $50 \mathrm{~mm}$. Hg. During the past decade, however, various studies (Heath and Best, 1958; Granston, 1958; Wagenvoort, 1960; Aber, 1961) have established that the medial thickness of the normal small pulmonary artery rarely exceeds 5 per cent of the external diameter, the upper limit of normal being 6.8 per cent. Hence we have employed in the present investigation these lower figures as the criteria of medial hypertrophy, and we have found 
TABLE III

PULMONARY HAMODYNAMICS AND MITRAL VALVE SIZE

\begin{tabular}{|c|c|c|c|c|c|c|}
\hline \multirow{2}{*}{ Case No. } & \multirow{2}{*}{$\begin{array}{l}\text { Left atrial } \\
\text { mean pressure } \\
(\mathrm{mm} . \mathrm{Hg})\end{array}$} & \multirow{2}{*}{$\begin{array}{c}\text { Pulmonary artery } \\
\text { mean pressure } \\
(\mathrm{mm} . \mathbf{H g})\end{array}$} & \multirow{2}{*}{$\begin{array}{l}\text { Cardiac index } \\
\left(1 . / \mathrm{min} . \mathrm{m} .^{2}\right)\end{array}$} & \multirow{2}{*}{$\underset{\text { (units } \mathbf{m} \cdot \cdot^{2} \text { ) }}{\text { PVR }}$} & \multicolumn{2}{|c|}{ Valve size } \\
\hline & & & & & Diam. (cm.) & Sq. cm. m. ${ }^{2}$ \\
\hline $\begin{array}{r}1 \\
2 \\
3 \\
4 \\
5 \\
6 \\
7 \\
8 \\
9 \\
10 \\
11 \\
12 \\
13 \\
14 \\
15 \\
16 \\
17 \\
18 \\
19 \\
20\end{array}$ & $\begin{array}{l}15^{\star} \\
15^{\star} \\
12^{\star} \\
7 \\
18^{\star} \\
20 \\
15^{\star} \\
12 \\
15 \\
14^{\star} \\
20^{\star} \\
5 \\
25 \\
20 \\
12^{\star} \\
10 \\
20 \\
15^{\star} \\
8\end{array}$ & $\begin{array}{l}30 \\
40 \\
17 \\
40 \\
25 \\
35 \\
45 \\
25 \\
30 \\
20 \\
40 \\
11 \\
45 \\
40 \\
16 \\
25 \\
45 \\
20 \\
15\end{array}$ & $\begin{array}{l}2 \cdot 2 \\
2 \cdot 3 \\
2 \cdot 1 \\
1 \cdot 2 \\
2 \cdot 2 \\
2 \cdot 7 \\
2 \cdot 9 \\
3 \cdot 6 \\
2 \cdot 1 \\
1 \cdot 8 \\
- \\
3 \cdot 5 \\
2 \cdot 5 \\
2 \cdot 4 \\
3 \cdot 0 \\
2 \cdot 2 \\
2.6 \\
3 \cdot 3\end{array}$ & $\begin{array}{r}7.3 \\
10.7 \\
2.5 \\
27.5 \\
3.2 \\
5.6 \\
11.4 \\
3.4 \\
7.3 \\
3.3 \\
- \\
5.8 \\
8.5 \\
1.6 \\
5.0 \\
11.2 \\
1.7 \\
2.5\end{array}$ & $\begin{array}{c}1.0 \\
1.0 \\
1.0 \\
1.0 \times 0.8 \\
0.75 \\
0.75 \\
1.0 \times 0.8 \\
1.0 \\
1.0 \times 1.5 \\
0.75 \\
= \\
1.0 \\
1.0 \\
1.0 \times 0.75 \\
1.25 \\
0.75 \\
1.0 \\
1.0 \\
1.0 \times 0.5\end{array}$ & $\begin{array}{l}0.48 \\
0.47 \\
0.46 \\
0.37 \\
0.28 \\
0.32 \\
0.45 \\
0.46 \\
0.68 \\
0.27 \\
-\overline{-} \\
0.55 \\
0.64 \\
0.38 \\
0.73 \\
0.32 \\
0.46 \\
0.47 \\
0.28\end{array}$ \\
\hline
\end{tabular}

* Pulmonary arterial wedge pressure.

PVR, pulmonary vascular resistance.

TABLE IV

RESULTS OF RESPIRATORY FUNCTION TESTS

\begin{tabular}{|c|c|c|c|c|c|c|c|}
\hline \multirow{2}{*}{ Case No. } & \multicolumn{2}{|c|}{ Vital capacity } & \multicolumn{2}{|c|}{ Maximum breathing capacity } & \multirow{2}{*}{$\frac{\mathrm{FEV}_{1}}{\mathrm{VC}}$} & \multicolumn{2}{|c|}{ Diffusing capacity } \\
\hline & Litres & $\% \mathbf{P N}$ & $1 . / \mathrm{min}$ & $\% \mathrm{PN}$ & & $\mathrm{ml} . / \mathrm{min} . / \mathrm{mm} . \mathrm{Hg}$ & $\% \mathbf{P N}$ \\
\hline $\begin{array}{r}1 \\
2 \\
3 \\
4 \\
5 \\
6 \\
7 \\
8 \\
9 \\
10 \\
11 \\
12 \\
13 \\
14 \\
15 \\
16 \\
17 \\
18 \\
19 \\
20\end{array}$ & $\begin{array}{l}2.2 \\
2.8 \\
3.3 \\
4.2 \\
2.6 \\
1.7 \\
3.0 \\
4.0 \\
2.0 \\
2.2 \\
- \\
2.1 \\
2.3 \\
3.4 \\
2.4 \\
2.1 \\
3.7 \\
3.4 \\
1.9\end{array}$ & $\begin{array}{r}75 \\
68 \\
100 \\
97 \\
90 \\
62 \\
110 \\
90 \\
71 \\
80 \\
- \\
73 \\
93 \\
110 \\
57 \\
80 \\
110 \\
103 \\
67\end{array}$ & $\begin{array}{l}32 \\
44 \\
83 \\
69 \\
50 \\
22 \\
56 \\
70 \\
30 \\
53 \\
\\
30 \\
32 \\
45 \\
44 \\
33 \\
87 \\
83 \\
29\end{array}$ & $\begin{array}{l}38 \\
55 \\
86 \\
62 \\
68 \\
28 \\
70 \\
61 \\
40 \\
57 \\
- \\
35 \\
46 \\
48 \\
45 \\
42 \\
90 \\
93 \\
39\end{array}$ & $\begin{array}{l}68 \\
80 \\
79 \\
65 \\
79 \\
78 \\
67 \\
62 \\
62 \\
83 \\
- \\
91 \\
53 \\
83 \\
72 \\
80 \\
70 \\
77 \\
60\end{array}$ & $\begin{array}{c}21 \cdot 4 \\
20 \cdot 4 \\
20 \cdot 9 \\
5 \cdot 1 \\
22 \cdot 2 \\
20 \cdot 3 \\
17 \\
30 \cdot 5 \\
20 \cdot 5 \\
22 \cdot 4 \\
- \\
- \\
9 \cdot 5 \\
5 \cdot 1 \\
23 \cdot 2 \\
15 \\
14 \cdot 8 \\
22 \cdot 3 \\
15.6 \\
26.6\end{array}$ & $\begin{array}{r}90 \\
100 \\
110 \\
20 \\
95 \\
100 \\
85 \\
122 \\
99 \\
92 \\
- \\
-46 \\
31 \\
96 \\
60 \\
76 \\
87 \\
63 \\
124\end{array}$ \\
\hline
\end{tabular}

PN, predicted normal; $\mathrm{FEV}_{1}$, one-second forced expiratory volume; VC, vital capacity.

that this degree of vascular abnormality is associated with a much lower level of pulmonary arterial pressure.

Complete hæmodynamic and histological data were obtained in 15 instances. In 11 , the pulmonary vascular resistance equalled or exceeded 3.3 units $\mathrm{m} .{ }^{2}$ as previously defined, and in all these there was medial hypertrophy in the pulmonary arteries as defined above. In all but one there was an abnormal muscular media in the pulmonary arterioles. Of the 4 patients with a lower vascular resistance (Cases 3, 5, 18, and 20), all had normal pulmonary arterioles, 2 (Cases 3 and 5) had normal muscular pulmonary arteries also, but the others showed a slight increase in the medial thickness of these vessels. The degree of medial hypertrophy defined by these stricter criteria clearly represents the earliest stage of hypertensive pulmonary vascular disease associated with a rise of pulmonary vascular resistance to only just above normal. In this respect, Aber (1961) commented that he found less evidence of medial hypertrophy than was reported in our previous series. He believes that this is due to the fact that our earlier series of patients 
TABLE V

HISTOLOGICAL DATA

\begin{tabular}{|c|c|c|c|c|c|c|c|c|c|}
\hline \multirow{2}{*}{ Case No. } & \multirow{2}{*}{$\begin{array}{c}\text { Hrmo- } \\
\text { siderosis }\end{array}$} & \multicolumn{3}{|c|}{ Dilated lymphatics } & \multirow{2}{*}{$\begin{array}{l}\text { Alveolar } \\
\text { fibrosis }\end{array}$} & \multirow{2}{*}{$\mathrm{CM}$} & \multirow{2}{*}{$\mathrm{IF}$} & \multirow{2}{*}{$\begin{array}{l}\text { Muscular } \\
\text { arterioles }\end{array}$} & \multirow{2}{*}{$\begin{array}{l}\text { HPVD } \\
\text { Grade }\end{array}$} \\
\hline & & Pleural & Fissural & Perivascular & & & & & \\
\hline $\begin{array}{r}1 \\
2 \\
3 \\
4 \\
5 \\
6 \\
7 \\
8 \\
9 \\
10 \\
11 \\
12 \\
13 \\
14 \\
15 \\
16 \\
17 \\
18 \\
19 \\
20\end{array}$ & $\begin{array}{l}+ \\
+ \\
+ \\
0 \\
0 \\
+ \\
0 \\
+ \\
0 \\
0 \\
0 \\
0 \\
0 \\
0 \\
+ \\
0 \\
+ \\
0 \\
0 \\
0 \\
0\end{array}$ & $\begin{array}{l}0 \\
0 \\
+ \\
+ \\
+ \\
+ \\
+ \\
0 \\
0 \\
0 \\
+ \\
0 \\
0 \\
+ \\
0 \\
+ \\
0 \\
0 \\
0\end{array}$ & $\begin{array}{l}+ \\
+ \\
+ \\
+ \\
+ \\
+ \\
0 \\
0 \\
0 \\
+ \\
+ \\
+ \\
+ \\
+ \\
0 \\
+ \\
+ \\
+ \\
+ \\
+\end{array}$ & $\begin{array}{l}+ \\
0 \\
0 \\
+ \\
0 \\
0 \\
0 \\
0 \\
0 \\
0 \\
0 \\
0 \\
+ \\
0 \\
0 \\
0 \\
0 \\
0 \\
0\end{array}$ & $\begin{array}{l}0 \\
+ \\
0 \\
0 \\
+ \\
0 \\
+ \\
0 \\
+ \\
+ \\
0 \\
0 \\
+ \\
+ \\
0 \\
0 \\
0 \\
0 \\
0 \\
+\end{array}$ & $\begin{array}{r}17.3 \\
11.1 \\
5.8 \\
13.4 \\
5.8 \\
9.0 \\
77.6 \\
11.6 \\
-8.6 \\
8.4 \\
6.4 \\
6.7 \\
13.7 \\
16.3 \\
\overline{9.4} \\
11.1 \\
10.0 \\
\overline{7.6}\end{array}$ & 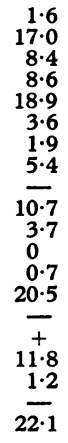 & $\begin{array}{l}+ \\
+ \\
0 \\
+ \\
0 \\
+ \\
+ \\
+ \\
+ \\
+ \\
+ \\
+ \\
+ \\
0 \\
+ \\
0 \\
0\end{array}$ & $\begin{array}{l}3 \\
3 \\
0 \\
3 \\
0 \\
3 \\
3 \\
3 \\
3 \\
3 \\
0 \\
3 \\
3 \\
1 \\
3 \\
3 \\
3 \\
1 \\
3\end{array}$ \\
\hline
\end{tabular}

CM, thickness of circular muscle coat of pulmonary arteries expressed as a percentage of vessel diameter. IF, percentage of artery lumen obliterated by intimal fibrosis. HPVD, hypertensive pulmonary vascular disease.

had pulmonary hypertension which was more severe and chronic than that which occurred in his; only 2 of his patients had a medial thickness exceeding 15 per cent.

The present studies have confirmed our previous impression that while there is an association between pulmonary vascular resistance and anatomical changes in the pulmonary vasculature, the correlation is not linear. This is not surprising, since in mitral stenosis, while the arteries in the lower zones may show medial hypertrophy, those in the upper zones show much less pronounced changes and may even be normal (Harrison, 1958; Heath and Best, 1958; Harrison, 1960). According to Aber, the closest relation appears to be between what he terms the "pathological index," which he defines as the function of intravascular pressure and its duration, and the lumen-to-wall ratio in the muscular pulmonary arteries and arterioles. When this index exceeds 200 in the case of arteries and 300 in the case of arterioles there is a marked reduction in the lumen-to-wall ratio of these vessels.

The results of our investigation show that there is some relation between the development of intimal fibrosis and the height of pulmonary vascular resistance. All the patients with a pulmonary vascular resistance exceeding 3.3 units $\mathrm{m} .^{2}$ in whom histological data were available showed intimal fibrosis in the pulmonary arteries, i.e. all exhibited grade 3 hypertensive pulmonary vascular disease. However, as in the case of medial hypertrophy, there is no linear correlation between the level of pulmonary vascular resistance and the extent of occlusion of the lumen by intimal fibrosis.
From the data collected it is clear that the majority of cases of pulmonary hæmosiderosis are detectable by radiological examination which is, however, too insensitive to pick up every case. Of the 7 patients shown to have pulmonary hæmosiderosis by histology, only 5 had had the condition detected radiologically. Aber (1961) also found that moderate or severe hæmosiderosis of the lingula may occur when the condition is not detected radiologically. We have found no relation between the existence of hæmosiderosis and the height of pulmonary venous pressure. This confirms our previous finding of hæmosiderosis in 3 of 16 patients with a pulmonary venous pressure of less than $20 \mathrm{~mm}$. $\mathrm{Hg}$ and 6 out of 17 with the corresponding pressure above this level (Heath and Whitaker, 1956). Aber (1961) also found no relation between the level of left atrial blood pressure and histological or radiological evidence of pulmonary hæmosiderosis; he comments that pronounced radiological hæmosiderosis may be associated with mild or severe pulmonary hypertension. We believe that pulmonary hæmosiderosis results from the rupture of distended capillaries in the lungs and that this can occur even when the pressure in the pulmonary veins and arteries is normal at rest. Gough (1960) regards these conclusions as unreliable on the ground that the biopsies employed in such investigations have been taken from the lingula. He states that the lingula extends down level with the base of the lung, and he believes that these basal areas of the lung not infrequently contain less hæmosiderin than elsewhere. This criticism does not answer the point that we have 
found hæmosiderosis in the lingula too frequently, rather than too rarely, to be in accord with the classical pathological concept of "brown induration of the lung" in mitral stenosis as the result of chronic pulmonary venous hypertension. However, there does not appear to be any relation between the presence of pulmonary hæmosiderosis and a history of frank hæmoptysis: only 2 of the 4 patients giving a history of this symptom had hæmosiderosis on histological examination. There appears to be no relation between the incidence of histological hæmosiderosis and alteration in pulmonary function, or with the degree of dyspnca, though Aber (1961) found evidence to suggest that in some patients with severe pulmonary hæmosiderosis the functional incapacity was pronounced.

All 6 patients with radiological evidence of enlarged pulmonary arteries showed medial hypertrophy of the muscular pulmonary arteries and the development of muscularized pulmonary arterioles. Of the 9 patients with equivocal radiological evidence of enlargement of the main pulmonary arteries, histological information was available in 6 . In $\mathbf{5}$ of these the muscular pulmonary arteries were abnormal, but the degree of increased medial thickness in these subjects was comparable with those showing radiological evidence of pulmonary arterial hypertension. Of the 5 patients whose pulmonary arteries were radiologically normal, 3 also showed increased medial thickness of the small pulmonary arteries. These findings reveal that while all patients with mitral stenosis and definite radiological evidence of pulmonary artery enlargement, and the majority of those with equivocal evidence of such change, will have organic hypertensive pulmonary vascular disease, there is no direct relation between the degree of pulmonary arterial dilatation and vascular abnormality. This confirms the previous impression of Whitaker and Lodge (1954) who found that while enlargement of the main pulmonary artery and its branches is a sign of pulmonary hypertension, it is no index of its degree. Here our findings are at variance with those of Aber (1961) who believes that the pulmonary arterial blood pressure can be reasonably accurately assessed from the routine postero-anterior chest radiograph. We have been unable to confirm his impression that a relation can be established between the severity of the pathological changes in the small pulmonary arteries, including the degree of intimal fibrosis as seen in the lingula, and the degree of radiological enlargement in the main artery and its branches in mitral stenosis.

Transient basal horizontal lines in chest radiographs are generally held to be a sign of pulmonary venous hypertension. Rossall and Gunning (1956) found for example that such lines invariably appeared when the mean pressure in the left atrium exceeded $24 \mathrm{~mm}$. Hg. Transient basal horizontal lines have been attributed to interstitial œedema of the connective tissue septa and to gross dilatation of the pulmonary lymphatics. Such pulmonary "lymphangiectasis" is prominent in biopsies when the left atrial pressure exceeds $30 \mathrm{~mm}$. $\mathrm{Hg}$ (Heath and Hicken, 1960). In the present investigation the left atrial pressure never exceeded this level in any of the patients studied and prominent pulmonary lymphangiectasis was not seen. We have previously shown (Heath and Hicken, 1960) that if this condition of lymphangiectasis is absent, the measurement of individual lymphatic vessels in connective tissue septa, pleura, and around arteries is valueless as a method of detecting pulmonary venous hypertension, since there is no direct relation between the degree of lymphatic dilatation and the level of pulmonary venous or left atrial pressure. In our present study we have been unable to demonstrate any relation between the presence of enlarged lymphatics and the occurrence of horizontal lines in the chest radiographs. There was, however, a relation between horizontal lines on the chest radiograph and fibrosis of the alveolar walls, as this occurred in none of the patients whose radiographs showed no horizontal lines and in 8 of the 13 patients whose radiographs did show lines. Since the lines are altered within a short time by rest or treatment, they cannot be due to fibrosis, but we feel that they are due to odema of the alveolar wall, which in turn results in fibrosis. Aber (1961) also found that radiological evidence of basal lines was associated with histological changes of fibrosis of alveolar walls, and in addition that this pathological finding occurred only when the pulmonary function was abnormal. We have not been able to confirm the latter finding.

The relation between structural abnormalities in the alveolar walls and the results of respiratory function studies was poor. The diffusing capacity was not related to the presence or degree of fibrosis of alveolar walls, nor were the vital capacity or maximum breathing capacity. This finding may be explained by the patchy nature of the anatomical changes, which makes it almost impossible to assess its functional significance in individual biopsies and renders any attempt at grading the degree of alveolar fibrosis exceedingly difficult. For this reason we have contented ourselves with simply deciding whether fibrosis of alveolar walls was present or absent. A final complication is that in addition to the local patchy nature of the lesion it is almost certain that alveolar fibrosis would be more pronounced in the lower than in the upper lobes or 
lingula, and the respiratory function tests which we have measured give only over-all results for the whole of both lungs.

The present study and that of Aber (1961) agree that there is no relation between the pulmonary diffusing capacity and the presence of fibrosis in the alveolar walls, but that the patients with low diffusing capacities generally have evidence of hypertensive pulmonary vascular disease. It seems that impairment of the diffusing capacity in mitral stenosis depends less on the structure of the alveolar wall than on the presence of occlusive pulmonary vascular changes.

In the present investigation we have found a closer association between the symptom of dyspnoea and the pulmonary vascular lesions present than with the presence of fibrosis of alveolar walls. There was no demonstrable correlation between the anatomical changes in the alveolar wall as noted in the lung biopsy and the grade or duration of dyspnoea, though the one patient who had insignificant dyspnœa showed no alveolar fibrosis. On the other hand there was some correlation between the degree of intimal fibrosis in the small pulmonary arteries and both the grade and duration of symptoms. Only 2 of the 8 patients with symptoms for three years or less in whom histological studies were made showed significant intimal fibrosis (exceeding $5.5 \%$ ) whereas 6 of the 9 patients with symptoms for longer than this showed prominent intimal proliferation. Again all 8 patients with severer symptoms (grades 3 and 4), where biopsy material was available, had grade 3 hypertensive pulmonary vascular disease, whereas only 4 of 11 patients with milder dyspncea had this degree of vascular abnormality. In other words the duration and severity of dyspnoea was roughly related to the grade of hypertensive pulmonary vascular disease present.

\section{SUMMARY}

A histological study of lingular biopsies from 20 patients with mitral stenosis has been made, and the pathological features' have been related to the symptomatology, to the radiological appearances of the lungs, and to abnormalities in pulmonary function and pulmonary hæmodynamics.

Medial hypertrophy in the small "muscular pulmonary arteries", defined as a medial thickness exceeding 6.8 per cent of the external diameter of the vessel, and muscularization of the pulmonary arterioles were found when the pulmonary vascular resistance exceeded only 3.3 units $\mathrm{m} .{ }^{2}$ There was no linear relation between the degree of medial hypertrophy and the height of pulmonary vascular resistance.
Pulmonary hæmosiderosis was found in only about one-third of patients, most of whom also had radiological evidence of hæmosiderosis. Its presence was not related to the height of the pulmonary venous pressure.

Radiological evidence of enlargement of the main pulmonary arteries is an indication of the presence of pulmonary arterial hypertension (and associated hypertensive pulmonary vascular disease) but not of its degree.

"Pulmonary lymphangiectasis" does not occur with moderate rises in left atrial pressure. Horizontal lines on the chest radiograph are not related to the presence of dilated lymphatics in the biopsy but to the presence of alveolar fibrosis. Both conditions are probably the result of œdema in the lung tissue.

The relation between structural changes in the alveolar wall and respiratory function is poor. Diffusing appears to be more closely related to pulmonary vascular disease than to changes in the alveolar walls. The severity and duration of dyspnœa is related to the grade of hypertensive pulmonary vascular disease.

\section{REFERENCES}

Aber, C. P. (1961). The lungs in mitral stenosis. The physiological and radiological assessment of the lungs in relation to the hæmodynamic and pathological changes in the lesser circulation. M.D. Thesis, University of Leeds.

Arnott, W. M. (1963). The lungs in mitral stenosis. Brit. med. F., $2,765$.

Baldwin, E. de F., Cournand, A., and Richards, D. W., Jr. (1948). Pulmonary insufficiency. I. Physiological classification, clinical methods of analysis, standard values in normal subjects. Medicine (Baltimore), 27, 243.

Gough, J. (1960). Diseases of the lung. In Recent Advances in Pathology, 7th edn., ed. C. V. Harrison, p. 54. Churchill, London.

Granston, A. S. (1958). Morphologic alterations of the pulmonary arteries in congenital heart disease. Proc. Inst. Med. Chic., 22, 116.

Harrison, C. V. (1958). The pathology of the pulmonary vessels in pulmonary hypertension. Brit. F. Radiol., (n.s.), 31, 217.

- (1960). Diseases of arteries. In Recent Advances in Pathology, 7th edn., ed. C. V. Harrison, p. 150. Churchill, London.

Heath, D., and Best, P. V. (1958). The tunica media of the arteries of the lung in pulmonary hypertension. F. Path. Bact., 76, 165.

—, and Edwards, J. E. (1958). The pathology of hypertensive pulmonary vascular disease. A description of six grades of structural changes in the pulmonary arteries with special reference to congenital cardiac septal defects. Circulation, 18, 533.

- , and Hicken, P. (1960). The relation between left atrial hypertension and lymphatic distension in lung biopsies. Thorax, 15, 54. 
Heath, and Whitaker, W. (1955). The pulmonary vessels in mitral stenosis. F. Path. Bact., 70, 291.

- - , and - (1956). The relation of pulmonary hæmosiderosis to hypertension in the pulmonary arteries and veins in mitral stenosis and congenital heart disease. F. Path. Bact., 72, 531.

Ogilvie, C. M., Forster, R. E., Blakemore, W. S., and Morton, J. W. (1957). A standardized breath holding technique for the clinical measurement of the diffusing capacity of the lung for carbon monoxide. $\mathcal{F}$. clin. Invest., 36, 1 .
Rossall, R. E., and Gunning, A. J. (1956). Basal horizontal lines on chest radiographs: significance in heartdisease. Lancet, 1, 604 .

Wagenvoort, C. A. (1960). Vasoconstriction and medial hypertrophy in pulmonary hypertension. Circulation, 22, 535.

Whitaker, W., and Lodge, T. (1954). The radiological manifestations of pulmonary hypertension in patients with mitral stenosis. f. Fac. Radiol. (Lond.), 5, 182. 